\title{
Modeling Buying Pattern in Emerging Indian Urban Families
}

\author{
Megha Virmani \\ House No - 1607,_Sector - 7E, Faridabad - 121006, Haryana \\ Email: virmanimegha@gmail.com
}

Accepted: March 17, 2013 Published: May 01, 2013

Doi:10.5296/jsr.v4i1.3617ＵRL: http://dx.doi.org/10.5296/jsr.v4i1.3617

\begin{abstract}
Marketing in India is growing through an indefinable phase. In addition to this is the changing role of consumer (from the "Karta" of the family to the kid) in making decision and the way in which the new generation Indian consumer behaves. In today's global marketing era, where market is offering, diversity of consumer preference, his decision has become more important in changing environment. Many new upcoming trends have been seen in these decades.
\end{abstract}

A traditional family in India is different from a western family in that the "empty nest" stage of the family life cycle is not very common. The decision making process for the purchasing of consumer durables is quite elaborate, as many members with their diverse view are involved in it. At the same time, the characteristics of Indian families are changing under the influence of external factors such as liberalization and media explosion. Indian families are presently in a state of flux, shifting from being strictly hierarchical to more egalitarian in character. Knowledge about buyer behavior is necessary for the development of effective marketing strategies. The members of a family influence the decision-making process in the purchase of different products; therefore the real target for the marketer is not an individual member but the family as a whole.

While there have been several studies on family dynamics in decision-making, very few pertain particularly to the Indian context, where the traditional family is different from its Western counterpart in that the 'empty nest' stage of the family life cycle is not very common. A large number of Indian families still have three generations staying together. A marketer has to compete not only with other brands in his product category but also with different product categories. This becomes even more significant when the family is considered as a unit where the needs of several members have to be met from the limited funds. It is then important for the marketer to understand the intra-family dynamics and inter-personal relationships at play in the purchase of a consumer durable product in order to decide the optimal marketing-mix.

Consumer Decision making $[\mathrm{CDM}]$ is helpful for the marketer to focus on a specific stage of 
the process. The roles played by members of the family varies with demographics parameters as well as with the typed of products. While a number of psychological variables are useful in obtaining into consumer's psyche, it is worthwhile to probe into some specific aspects of consumer decision making in order to formulate marketing strategies. CDM enables marketers to visualize a broad framework of stage and apply psychological or/ and group variables to a specific product/ market/ brand situation. The influencer plays an important role in CDM. Unlike the organizational buying process, in the case of a family, the influencer does not usually have expertise but assume their respective roles on the basis of the family dynamics.

The different models emerged in the area of business services which include market research and advertising agency, concentrated on buying pattern of consumer so that overall satisfaction will be evolved. As we know that in family different members play different roles such as moderator, communicator, convincer, informator, motivator etc. so it is very difficult for marketer to understand family members and their needs so the concept of closing sales will be evolved as it is required to develop a model where we can find out the pros and cons of buying pattern of Indian Urban Families.

The idea of choosing this topic of redefining is to differentiate between the traditional buying pattern and modern buying pattern based upon the buying capacity. Today, is the era of modernization. consumer is aware educated, new concept are emerging to attract him( e.g.: mall culture, retailing boom, large number of MNC bank establishing, changing of concept of living, emerging new opportunity, increasing literacy, increasing professional education in NCR, investment in infrastructure, introducing metro etc). looking the above parameter the idea of redefining of buying roles of urban families is an important are to study.

\section{INTRODUCTION}

\section{The concept of family}

Although family seems to be an intuitive term, it is difficult to define because family composition and the structure, as well as the roles played by family members are almost always in transition.

A family is defined by the bureau of the census of the US as "two or more persons related by blood, marriage, or adoption and living together". The area of family research considers the family as a unit of analysis. Family research attempts to describe and understand how family members interact and influence one another in terms of individual, household purchase.

Kotler asserts that there are two families in the buyer's life - the family of orientation and the family of procreation. The family of orientation consists of one's parents and siblings, from where a person acquires an orientation towards religion, politics, and economics, and a sense of personal ambition, self - worth and love. The family of procreation consists of one's 
spouse and children who have a more direct influence on everyday buying behavior.

In India and in few more countries, the joint family system was prevalent in earlier times where all the members of the family consisting of uncles, aunts, their children, grandparents, and all other having the share in the property live together.

The family as a unit is an important consumer for many products, which are purchased for consumption by all family members. thus the same decision in many families may be made either by the husband or by the wife or both may have a equal voice. Children are also beginning to exert their influence on the family purchase decisions.

\section{Functions of the Family}

The functions of the family vary from culture to culture and also from one family to other. Basically the family performs four types of functions for its members i.e. providing financial support, emotional support, family lifestyle and socialization.

Traditionally, the husband was responsible for providing the economic well being. But with the rise in the working wives and teenage children doing part - time job, the economic role has changed. Family provides emotional support and assists its members to cope with the personal and social problems. Family also establishes a suitable life style for its members determining the importance to be placed on education, career, reading, selection of entertainment and recreational activities and dressing up etc.which influence their consumption pattern. Moreover family helps in socializing its members, imparting to children and other members the basic values and modes of behavior consistent with the culture.

\section{Family Decision Making}

Family decision -making basically refers to the manner in which family members interact and influence each other when making purchase choices for the household. Although a family is being recognized as the basic decision - making unit, marketers most frequently examine attitudes and behavior of one family member whom they believe to be the major - decision maker. To fully understand family decision - making, marketers need to identify which family members take on what roles. Family Roles can be categorized as:

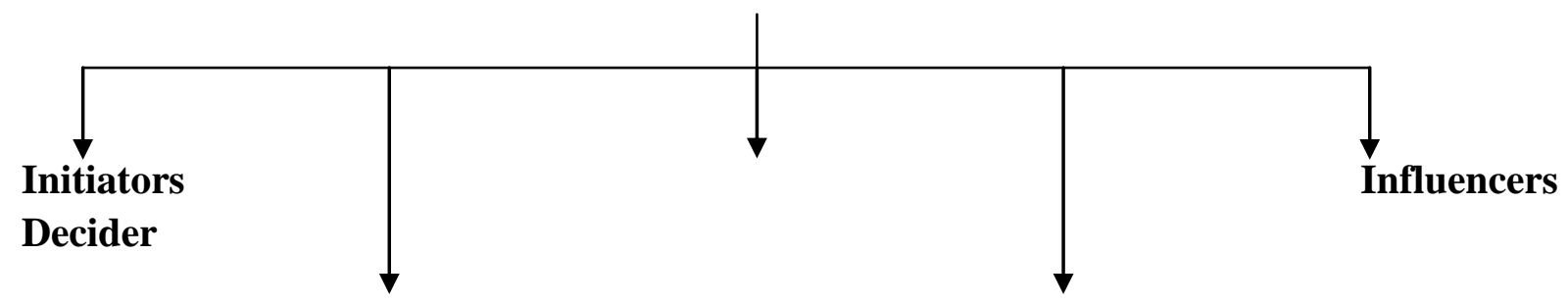

\section{Buyer}


User

1 Initiator is the person who first suggests the idea of buying the product or service.

2 Influencer is the person whose view or advice influences the decision.

3 Decider is the person who decides on any component of a buying decision: whether to buy, what to buy, how to buy, or where to buy.

4 Buyer is the person who makes actual purchase.

5 User is the person who consumes or uses the product or service.

\section{Family Life - Cycle}

Family is a dynamic entity. The composition of a family changes over time and with that the family needs, behavior of its members and the decision making process also change. The change in the composition in family is known as "Family Life Cycle".

Wells and Guber have proposed the following eight - stage framework for a consumer oriented family life cycle.

\begin{tabular}{|l|l|l|}
\hline S.NO & STAGES & EXPLAIN \\
\hline 1 & Bachelor stage & Young, single, not living at home. few financial burdens. \\
\hline 2 & $\begin{array}{l}\text { Newly Married } \\
\text { couples }\end{array}$ & $\begin{array}{l}\text { Young, no children. Highest purchase rate and highest } \\
\text { average purchase of durables. }\end{array}$ \\
\hline 3 & Full Nest I & Youngest child under six. Home purchasing at peak. \\
\hline 4 & Full Nest II & Youngest child six or over. Financial position better. \\
\hline 5 & Full Nest III & $\begin{array}{l}\text { Older married couples with dependent children. Financial } \\
\text { position still better. }\end{array}$ \\
\hline 6 & Empty Nest I & $\begin{array}{l}\text { Older married couples, no children living with them, head of } \\
\text { household in labor force. home ownership at peak. Most } \\
\text { satisfied with financial position and money saved. }\end{array}$ \\
\hline 7 & Empty Nest II & $\begin{array}{l}\text { Older married. No children living at home, head of } \\
\text { household retried. Buy medical appliances, medical - care } \\
\text { products. }\end{array}$ \\
\hline 8 & Solitary Survivor & In labor force. Income still good but likely to sell home. \\
\hline 9 & Solitary Survivor & $\begin{array}{l}\text { Retired. Same medical and products needs as other retired } \\
\text { group; drastic cut in income. }\end{array}$ \\
\hline
\end{tabular}

\section{REVIEW OF STUDIES ON FAMILY PURCHASES: GLOBAL AND THE INDIAN EXPERIENCE}

This presents a review of the existing literature in order to gain insights into the research work undertaken in the area. 
SECTION - I Studies on Exploration of Product Categories and Family Decision Making

The following are the major studies, which deal with the exploration of product category differences, their relationship to family decision - making and the structure of husband and wife roles.

* Wolgast M. Elizabeth (October 1958) studied the role played by husbands and wives in making a purchase decision. Her study was based on a cross section of families in all parts of USA. It indicates that, in consumer surveys concerned with a broad range of expenditures, the husband and wife are equally desirable respondents.

* Webster Cynthia (September 1994) involves the conclusions drawn with regard to the regard to the traditional role specialization and purchase behavior: Traditional role specialization affects, which spouse has dominance with respect to specific products. Traditional role specialization influences the relative dominance with respect to products attributes.

* Qualls William J. (September 1987) examines the impact of sex orientation on the outcome of a family decision to purchase a house. A relatively strong relationship is found between sex role orientation and the degree of household influence, preference agreement, mode of conflict resolution and decision outcome.

* Komarovsky's Mirra ( 1961) indicated that joint involvement in decision - making is found to occur most in middle - income families and younger couples and is related to the extent of husband - wife communication. The study examined support the fact that the wife in the lower socio - economic hierarchy than among the middle class.

* Devis Haary L., Hoch Stephen J. and Easton E.K. Ragsdale (June 1986) predict the preferences of husband and wife. It proposes an anchoring process where an attempt is being made to adjust for the ways in which people differ from others.

* Sharp and Mott(1956) finds the traditional beliefs regarding the intra - familial assignment of consumer decision - making roles .There is a evidence that in a large number of families, one or the spouse make all the decisions with regard to car, life insurance, food, apartment, vacation, money and bills.

Ferber and Lee (1974) studies the influence of husband - wife in family purchase behavior using the concept of family financial officer (FFO), the family is found to be not homogenous in its financial and purchase behavior. Further it was found that if the husband is the FFO, the couple is more likely to save a higher proportion of income and would purchase automobile less frequently. 
* Blood and Wolfe (1960) focused on examining bivariate relationships involving the decision role structure of the household. He finds that Husband dominance in the household decision - making is directly related to cultural norms of the society. The power to make household decisions is related to the resources husbands and wives bring to the household. The husband influence in household decision behavior is directly related to income, education, and occupation.

* Cunningham and Green (1974) The Trend towards sex role egalitarianism in household purchasing roles is related to the increase in joint decision behavior. It Depicts the changes that occurred over the past eighteen years in the roles of the husband and wife in family purchase decision - making. The most dramatic change in decision roles found in the study occurred in respect to automobiles.

Wilkie's study (1975) provides the measures which influence family in four stages i.e. Problem recognition, search, alternative evaluation and purchase of choice. His Process measures the following: Who was responsible for the initial problem recognition? Who was responsible for acquiring information about the purchase alternatives? who made the final decision as to which alternative should be purchased? Who made the actual purchase of the product?

\section{SECTION - II Studies On Investigation Of Determinants Of Joint Decision - Making Under Conflicting Goals}

The major studies on joint decision -making under conflicting goals are reviewed below:

* Davis and Rigaux (1974) explored the relative influence of the husband and the wife during three major phases in purchasing, namely, problem recognition, the search for information and final decision. Interestingly there is a greater tendency for joint input during the problem recognition and final decision stages. He classified decisions as syncretism when both the husband and wife are involved in decisions together; autonomic when decisions are usually made independently, and husband or wife - dominant when the decision to purchase was primarily influenced by one or the other.

* Corfman and Lehmann (1987) develop a conceptual framework that provides a description of the group decision - making process in conflict situations. The model tested includes the power - related resources and power use related goals as the determinants of relative influence. the results indicate that relative preference intensity and the outcome of preceding joint decisions consistently make the strongest contribution to relative influence.

* Menasco and Curry ( 1979) studies the effect of different information strategies on joint decisions. the findings of the study indicate that for high - priced durable products, the husband and wife must select one multi - attribute brand from a class of such brands. 
The study examines the different information processing strategies on pre - choice agreement about brand utilities and post - choice utility loss for each spouse as a result of their joint decision.

* Filiatrault and Brent Ritchie( 1980) states a comparison of the perceived influence within household decision - making units of different composition revealed substantial variations in the patterns of role dominance and response consensus. the result indicated that though children had relatively little perceived influence on the vacation and accommodation selection decisions, they still affected the outcome of particular choices.

* Seymour Daniel and Lessne Greg ( December 1984) studed a conflict arousal scale developed as a tool to conduct emprirical research in family decision making. The scale's reliability and validity were examined and reported. A general overview of the scale development procedure demonstrates that the conditional influence variable is scalable. The major goal was to facilitate future process - oriented research on the role of conflict in family decision making by presenting a reliable and valid scale for measuring spousal conflict arousal.

* Spiro's Rosann L. (March 1983) proposed and investigated six different types of influence strategies to be used to persuade family members depending on the product, family members involved, and the situation. As expert strategy, legitimate strategy, Bargaining Strategy, reward strategy, emotional strategy, impression management strategy.

* Park' Whan C. study (September 1982) analyzed how couples went about buying as well as avoiding conflicts. In fact instead of using, well planned procedure, park found a process described as muddling through. result show that in terms of partners decision plan themselves, both the husband and wife thought they had approached the decision in a similar way, when in fact their approaches had been quite different.

\section{SECTION - III Studies on Changing Roles of the Wife and Children}

The studies reviewed in this section primarily concentrate on the changing role of different family members and on double income - families, where wife plays an equal role in decision - making. Recently the role of children as consumers has increased at an unprecedented rate. Children do not form a homogenous group as their characteristics vary widely with respect to the age group to which they belong.

Gregan Jennifer and John Deborah Roedder (March 1995) According to this study, children are now - a - days called upon to take decisions not only about their own purchases but also about purchases made by family unit. It explores the emergence of adaptivity in the decision - making skills of young children especially focusing on young children pre - decisional search behavior and examines the extent to which they adapt 
their search behavior and examines the extent to which they adapt their search behavior to different levels of search costs and benefits in the decision environment.

* Foxman Ellen R, Patriya S. Tansuhay and Karin M. Estrom's (March 1989) compares the existing relationship between different family members i.e., father, mother, and adolescent child, to identify the structural relationships between parents and children in family decision - making. The results indicated that children exercise some influence in the purchase decisions of a variety of products that are less expensive and are intended for their use. the analysis indicated that the mother's and father's perception, though not in perfect agreement, were much closer to each other than were either parent's perceptions to that of the child.

* Beatty Sharon E. and Talpade Salil (September 1994) used an integrative model of teenager influence and a new scale of the perceived relative influence of younger children, when the purchases made are not for self use. It further examined the effect of the parental employment status on teen influence as well as gender - based differences in perception. In this study the financial resources and the product knowledge of the teens serve as the sources of their ability, while the perceived importance and usage of the product motivate

* Green Robert T and Isabella CM Cunningham (August 1975) studies the family decision -making patterns under different conditions of female role perception. The findings suggest differences between contemporary and traditional families, particularly within various age and income categories. the objective of the study was to examine the potential impact that changes in the female role would have on the family's purchasing patterns.

* Scott ward and Daniel Wackman (august 1975) examines the impact of three variables on children's purchase influence attempts and parental yielding, viz., demographics, parent - child interaction and mother's mass communication behavior. it was found that the influence of children in purchases varies across product categories.

Carron Andre and Scott Ward (August 1975)examined certain aspects of the relative influence of mass media and interpersonal sources on children's purchase desires and parental decision - making pertaining to their children's product desires.

* Syzbillo George J, Sosanie, Arlene K and Tenenbein ( December 1977) tries to explore how the family role structure inclusive of children, varies over sub - decisions taken within a generic service category.

- Burr, Pat L and Burr Richard M(December 1977) conducted a study to find out how parents respond when asked by children to buy products as a result of communication 
directed to children. it was found that the disposition of the parents to buy as a result of various appeals used by the children varies according to the appeal used.

* Nickelodeon's (December 1999) concluded that today kids are exerting unprecedented influence over the purchasing decisions made in their families, including decisions made in their families, including decisions for non kid specific kid specific products such as computer hardware and software. The survey also indicates that kids as young as six years of age are exhibiting a distinct awareness of brands.

- Reynold Fred D. and Wells William D ( 1977)found that children play an influencing role in family purchases. This takes place in various ways, viz. by making personal purchase; by making direct requests in the store; by making direct requests in the store; by making direct requests at home; and by passive dictation.

* Wells William D.and Loscuito Leonard (August 1966) founded that children accompany their parents while shoping and also exert influence on the purchases when they were present at the shops. Suburban parents were found to be more indulgent of their children than urban parents except the purchase of candy.

* Berey Lewis A. and Pollay Richard W (February 1968) investigated the child's influence on consumer decisions by studying the interaction between mother and child for the product class of 'ready to eat'. The extent of the child's influence on his parents decision was taken to be dependent on at least two factors: the child assertiveness and the parent's child centredness

\section{SECTION - IV Studies On Family Decision - Making In India.}

In India, a number of studies have been undertaken to identify the impact of various demographic factors like income, occupation, age, etc. on consumer behavior, but very few research studies have assessed the role played by various family members in the purchase of a product.

\section{* Study on role of family in consumer purchase decisions}

N. K. Aggarwalla (1978) examines the dimensions of husband - wife interaction in the purchase of durable and semi - durable products. It determines the extent of agreement between the husband and wife in purchase decisions. Further it illustrates how the perceptions of wife and husband, as individuals and as groups are influenced by variations in age, income, qualification and occupation of the respondents

\section{* Study on Indian Youth}

It indicates the following findings:

1. Pocket allowance vis $-\mathrm{a}-$ vis expenditure pattern.

2. Marketing variables and the young consumers 


\section{Macrothink}

3. Young consumers are influenced by various persons as influencers of family purchase decisions.

4. Reading and television interest of the young consumers.

\section{* Study on purchasing patterns of urban consumers}

It proposed to the marketers, particularly to retailers that they should plan there strategy not only to tap the growing market but also to suitably modify their present product lines with a change in the interest, fashion, and lifestyle of the adolescent consumers.

\section{Study on Dimensions of Marital roles}

Analysis showed that in majority of the families, it was the wife who perceived the need and initiated the process for the purchase of semi - durable product, followed by joint involvement of the spouses and at the end by the husband alone. An analysis of data showed that in a majority of the families, it was the wife who perceived of the semi - durable product, followed by the joint involvement of the spouses and at the end by husband alone. The ultimate decision of purchase was taken by husband alone in a majority of the cases.

\section{* Study on children buying behavior}

The study confines to the analysis of children's influence in the consumer buying behavior and how factors like income of the family, age of child, sex of the child, mothers qualifications and there employment status affect such influence. It also analyses the purchasing independence enjoyed by children. The study shows that the children in general make less purchase request. Children purchases request decline as the product becomes less relevant to them. The development of suitable Marketing Strategies necessitated, among other things, segmenting the market by relating, say the category of more specific purchase request to the demographic data of families to which the children belong.

\section{* Study on the urban Indian woman}

The analysis revealed that today's woman has a sense of personal identity and her emerging confidence will help her taking the purchase decision for family and own. the new Indian woman has a strong desire for personal achievement, reflected in her need to work outside the home and in her anxiety not to be called "the Typical Housewife" and to make her children embodiments of her personal achievement. Thus the fundamental change in today's Indian Woman is that there is a sense of personal identity. Communication strategies should therefore take the trends in to consideration. In the case of New age Indian women, both her emerging confidence as well as her angst on the lack of support to her emerging sense of self should be addressed.

\section{* Study on buying motives and role played by various family members}

There is a change in the buying patterns of the families. The decision is a more rational 


\section{Macrothink}

Journal of Sociological Research

ISSN 1948-5468

2013, Vol. 4, No.1

and final when consultation between a family is done and the purchase undertaken is considered useful for each and every one of the family.

\section{Summary}

- The focus of the above studies has been on family consumption decision. While numerous focused on the role played by husband or wife in a purchase situation and the influence of children.

- Since the above research work concluded a significant change in the buying behavior of Indian families as the question is all research work is done in the western part of the world and little in India E.g. Sheetal Kapoor.

- Now my involvement in the research work is to find out a model where you can distinguish the different role of the family members.

\section{Notes}

1. Leon G. Schiffman \& Leslie Lazar Kanuk, Consumer Behavior, $6^{\text {th }}$ Edition (Prentice Hall of India, New Delhi, 1997) Page. 346.

2. Ingrid C. Kildegaard, "A Household is Not a Family", Journal of Advertising Research, Vol. 7 (June 1967), pp. 44-46.

3. Peter J Paul and Olson C Jerry, Consumer Behavior: Marketing Strategy Perspectives (Richard D. Irwin, Homewood, III., 1987) P. 447.

4. Philip Kotler, Marketing Management: Analysis, Planning, Implementation and Control, $9^{\text {th }}$ ed. ( Prentice - Hall of India, New - Delhi, 1996), p. 179.

5. Leon G. Schiffman and Leslie lazar Kanuk, Consumer Behavior, 6ed ( prewntice Hall of India, New Delhi, 1997) p. 347.

6. Peter J. paul and Olson C. Jerry, Consumer Behavior, $3^{\text {rd }}$ Edition ( Richard D. Irwin, Homewood,III., 1993), pp. 515-516.

7. Raymond L. Horton, Buyer Behavior: A Decision Making Approach ( Charles E Merrill Publishing Company, New York, 1984), pp. 372 - 380.

8. John C. Mowen, consumer Behavior, $3^{\text {rd }}$ ed. ( Macmillian Publishing Company New York, 1993), pp. $598-608$.

9. William D. wells and George Guber, "Lifecycle Concept in Marketing Research", Journal of marketing - research, Vol 3( November 1966) pp. 12 - 22.

10. Elizabeth M. Wolgast, “ Do Husbands or Wives Make the Purchasing Decision?”, Journal of Marketing, Vol. 23 (October 1958), pp. 152 - 158.

11. ibid,pp. $156-158$

12. Cynthia Webster, "Effects of Hispanic Ethnic Identification on Martial roles in Purchase Decisions”, Journal of Consumer Research, Vol. 21 ( September 1994), pp. $319-331$

13. William J. Qualls , "Household Decision Behavior: The Impact of Husbands and wives sex role orientation”, Journal of Consumer Research, Vol. 14( September 1987), pp. $264-279$. 
14. Mirra Komarovsky, “ Class Differences in Family Decision Making”. consumer Behavior : Household Decision making, ( Nelson N. foot, university press, newyork, 1961 ), pp $264-279$.

15. Harry L. Davis, Stephen j. Hoch and E.K. Easton Ragsdale, “ An Anchoring and Adjustment model of spousal predictions", joural odf consumer research vol 13 (june 1986), pp. $25-37$.

16. Bernet Eleanor Sheldon , “ Family Decsion Making and economic behavior', Family Economic Behavior: Problems and prospects., pp 39-41.

17. Ellen R foxman, Patriuya S. Tansuhaj and Karin m . ekstrom, " family members perceptions of adolescents influrnce in family decision - making", Journal of consumer research, vol. 14 ( March 1989), pp. 482 - 491.

18. Georgew J. Sysbillo, sosanie, Arlene K and Tenendbein, aron " should children be suen buyt not heard", Journal of advertising esearch", vol 17 ( Decemvber 1977), pp. $7-13$.

19. Nickieledeon, “ separate research studies indicate today's kids having unprecedented influence o fsmily purchasing decisions", December 1999, pp.1-3.

20. Lewis A. berey and Richard W Pollay, " the influenving role of child in family decision making", Journal of marketing research, vol.5 (February 1968), pp. $70-72$ 